\title{
Lung function tests in different phases of menstrual cycle
}

\author{
Dudhamal V B ${ }^{1}$, Satish $^{2}$ \\ ${ }^{1}$ Dr. Vandana Dudhamal, Professor and HOD, ${ }^{2} \mathrm{Mr}$ Satish, Assistant Professor, Both are affiliated with \\ Department of Physiology, SMCRC, Guna, MP, India.
}

Address for Correspondence: Dr Vandana Dudhmal, Email: dudhamalv@gmail.com

\begin{abstract}
Introduction: Menstrual cycle is an integral part of a woman's life. During these different phases, rhythmic changes occur in the levels of ovarian hormones especially progesterone and estrogen. The goal of this study was to study the effect of the luteal and follicular phases of the menstrual cycle on bronchial reactivity (BR) in a group of women. Material and Methods: The fifty girl medical students of first year MBBS of $18-24$ years age were undertaken to study pulmonary function tests in different phases of menstrual cycle. Pulmonary function tests were taken between $8-10$ th day of menstrual cycle, that is in follicular phase and again were recorded between $20-22$ nd day of menstrual cycle that is in luteal phase by using spirometric technique. The results were expressed as Mean \pm Standard Deviation (Mean+ SD). Statistical analysis was done through Graph pad prism. Comparison of pulmonary function parameters in different phases of menstrual cycle was done by using one way ANOVA (Analysis of Variance) by bonferroni post-hoc test. Results: Anthropometric measurement of all subjects in which mean age was $19.45 \pm 1.80$ years, arm span was $157.25 \pm 6.37 \mathrm{~cm}$, chest circumference was $80.58 \pm 7.69 \mathrm{~cm}$, height was $149.07 \pm 4.64 \mathrm{~cm}$, weight was $45.65 \pm 6.69 \mathrm{Kgs}$. Spirometric study found FVC, FEV1, and PEFR increase in luteal phase of menstrual cycle compared to follicular phase, which were statistically significant. Conclusion: We found better lung functions which were statistically significant in luteal phase as compared to follicular phase of our subjects indicating a possible role of progesterone causing $\beta$ adrenergic stimulation / sensitization.
\end{abstract}

Keywords: Lung functions, Adolescent females, Progesterone, Luteal phase

\section{Introduction}

The increased vulnerability to inflammatory and autoimmune disease women experience after puberty is considered secondary to the different effect sex hormones have on the inflammatory defence system, and specifically on mast-cells (MC) $[1,2]$ and eosinophils cells. Fluctuations of estrogens trigger the mast-cell degranulation, whilst testosterone and other androgens are credited to have a stabilizing effect. Perimenstrual fluctuations of sex hormones in women are considered responsible for the specific worsening of many different perimenstrual symptoms and of specific inflammatory [3], autoimmune [4,5] and pain related conditions, such as headache and pelvic pain [6-10]. It has been known for a long time that some female asthmatic patients experience an

Manuscript received: $5^{\text {th }}$ July 2017

Reviewed: $15^{\text {th }}$ July 2017

Author Corrected: $24^{\text {th }}$ July 2017

Accepted for Publication: $29^{\text {th }}$ July 2017 aggravation of asthma symptoms during the premenstrual or menstrual phases of their cycle. In particular, it has been hypothesized that hormonal fluctuations during the menstrual cycle play a significant role in the pathophysiology of asthma, resulting in periodic worsening of disease severity in adult females [10-12].

Therefore, the goal of this project was to study the effect of the menstrual cycle; specifically, the luteal and follicular phases and plasma sex hormone levels, on bronchial reactivity (BR) in a group of asthmatic women. In particular, sex hormone levels and mediators of bronchial smooth muscle contraction were evaluated.

\section{Material and Methods}

The present study was conducted on the fifty girl medical students of first year MBBS of $18-24$ 
years age group. The subjects were selected from students studying in tertiary care teaching hospital attached with medical college in India. The subjects selected for the study were normal healthy young girls with no history of any disease, which could influence pulmonary function. The general and systemic examination of the subjects was done for all the systems with special emphasis on the respiratory system.

Inclusion criteria- Females of 18- 24 years age group having regular menstrual cycle of $26-30$ days.

Exclusion criteria- Age below 18 years and above 24 years age group, history of irregular menstrual cycle, subject on oral contraceptive pills and harmone replacement therapy.

Equipments- Spiro Excel Machine (Computerized spirometer) manufactured by Medicaid Systems, Chandigarh was used to measure the pulmonary Functions. The logic built into the Spiro Excel evaluates the patient/ subject as an adult or a child male or female and selected the suitable set of equation for computation of predicted norms.

Technical features of Spiro excel machine.- Flow meter Bi-directional digital turbine Range for flow measurement $0.03-20 \mathrm{~L} / \mathrm{Sec}$. Range for volume measurement $10 \mathrm{~L}$ Accuracy of measurement $3 \%$ or $50 \mathrm{ml}$ Dynamic resistance @ $12 \mathrm{~L} / \mathrm{Sec}<0.7 \mathrm{~cm}$ $\mathrm{H} 2 \mathrm{O} / \mathrm{L} / \mathrm{Sec}$. Mouthpieces 31 and $21 \mathrm{~mm}$ Power Supply No external supply required, works on $5 \mathrm{~V}$ from CPU Dimensions 160 × 50 × $25 \mathrm{~mm}$ Weight $100 \mathrm{gm}$

Method of collection of data- After explaining the aims and objectives of study written consent was taken from all the subjects.

All the subjects were given Proforma containing name, age in completed years, gender and dietary habits (whether vegetarian or non-vegetarian), history of smoking, whether active or passive and its duration, history of recurrent respiratory infections or significant past history of any other disease, family history of COPD (asthma or emphysema) and history of allergy, to be filled up. We recorded the menstrual history which specifically included date of last menstrual period (LMP), duration of menses, date of last three consecutive menstrual cycles. Data of all the subjects was acquired in the following three phases of menstrual cycle.

1. Menstrual phase

2. Proliferative phase

3. Secretory phase

Subjects were asked to report three times on the 2nd or 3rd, 10th -12th and 20th-22nd days of menstrual cycle. These days were calculated from LMP dates that were filled in the proforma. Pulmonary function tests were carried out of the subjects in the sitting position before lunch and values of different parameters were recorded.

Procedure for test administration

PFT were performed in calm and comfortable environment in 2 Steps.

1. Preparation

2. Test administration

\section{Preparation}

- It was ensured that the subjects were not wearing items of apparel that were tight or restrictive (e.g. necktie, buttoned shirt collar, tight belt etc.).

- Clean, disinfected mouthpiece was provided to every subject for the procedure

\section{Test administration}

- Clear and simple instructions were given to the subject followed by a demonstration.

- Nose was closed during the manoeuvre by nose clips.

- Mouthpiece was positioned in such a way that the subject's chin was slightly elevated and neck was extended.

- The subject was asked to exhale into the mouthpiece of Spiro Excel machine as forcefully as possible after deep inspiration. The test was repeated three times and the highest values were considered for analysis.

- In the manoeuvre each subject was motivated and encouraged to give her best performance.

Statistical Analysis- The results were expressed as Mean \pm Standard Deviation (Mean \pm SD). Statistical analysis was done through Graph pad prism. Comparison of pulmonary function parameters in different phases of menstrual cycle was done by using one way ANOVA (Analysis of Variance) by bonferroni post-hoc test. 


\section{Results}

The mean cycle length of all the subjects was in the range of $28 \pm 2$ days. Anthropometrical results of all the subjects are exhibited in table no. 1

Table No 1: Shows the anthropometric parameters of all the subjects $(n=50)$.

\begin{tabular}{|c|c|}
\hline Parameters & Mean \pm SD \\
\hline Age $($ years $)$ & $19.45 \pm 1.80$ \\
\hline Arm span $(\mathrm{cm})$ & $157.25 \pm 6.37$ \\
\hline Chest circumference $(\mathrm{cm})$ & $80.58 \pm 7.69$ \\
\hline Height $(\mathrm{cm})$ & $149.07 \pm 4.64$ \\
\hline Weight $(\mathrm{kg})$ & $45.65 \pm 6.69$ \\
\hline
\end{tabular}

Above table shows anthrpometric measurement of all subjects in which mean age is $19.45 \pm 1.80$ years, arm span is $157.25 \pm 6.37 \mathrm{~cm}$, chest circumference is $80.58 \pm 7.69 \mathrm{~cm}$, height is $149.07 \pm 4.64 \mathrm{~cm}$, weight is $45.65 \pm 6.69 \mathrm{~cm}$.

Table No 2: Exhibits the results of all pulmonary function tests Standard deviation.

\begin{tabular}{|c|c|c|c|}
\hline Parameters & Follicular phase & Luteal phase & P value \\
\hline FVC(L/SEC) & $2.01 \pm 0.40$ & $2.16 \pm 0.37$ & 0.001 \\
\hline FEV1(L/SEC) & $1.44 \pm 0.40$ & $2.16 \pm 0.37$ & 0.001 \\
\hline FEV3(L/SEC) & $2.13 \pm 0.55$ & $2.19 \pm 0.54$ & 0.721 \\
\hline PEFR(L/SEC) & $3.43 \pm 0.50$ & $4.00 \pm 1.28$ & 0.001 \\
\hline MVV(L/MIN) & $90.21 \pm 6.91$ & $90.36 \pm 30.06$ & 0.028 \\
\hline \multicolumn{4}{|c|}{ Significant $\mathrm{p} \leq 0.05$} \\
\hline
\end{tabular}

It is clear that FVC, FEV1, and PEFR show statistically increase in luteal phase of menstrual cycle compared to follicular phase. Which is statistically significant.

\section{Discussion}

In our study we found that, there was increase in FVC values in successive phases from menstrual to secretory phase. The FVC values of proliferative phase was significantly higher compared to menstrual phase $(p<0.001)$. Likewise the values of FVC were significantly higher in secretory phase as compared to proliferative phase $(\mathrm{p}<0.001)$. There are many similar studies with comparable results likewise.

Menstrual cycles are considered to be the chief protagonists in the clinical scenario of inflammation and pain [13-15]. Mast cells (MC) are present in the endometrium and myometrium and are predominantly localized to the basal layer [16]. Mast cells (MC) are upregulated in response to a wide range of stimuli, including neurogenic factors, fluctuating oestrogen levels and menstrual blood in the tissue [6]. Once activated, MC degranulate and release a range of inflammatory mediators which perpetuate the immune response [6]. Sex hormones regulate MC functionality and distribution in several tissues [17-19], both in physiological and pathological conditions. In this regard, a relationship between female sex hormones, MC and development of asthma and allergy has been suggested [20,21]. Furthermore, the presence of sex steroid receptors on MC indicates that sex hormones may exert their biological effects by binding to these receptors [21].

Alessandra Graziottin et al [22] found that PMA incidence is reported to vary between 19 and 40\% of asthmatic women. The presence of PMA has been related to increases in asthma- related emergency department visits, hospitalizations and emergency treatment including intubations. This paper will focus on the pathophysiology of hormone triggered cycle related inflammatory/ 
allergic events and their relation with asthma. We reviewed the scientific literature on Pubmed database for studies on PMA. Key word were PMA, mastcells, estrogens, inflammation, oral contraception, hormonal replacement therapy (HRT), and hormone free interval (HFI).

Dratva $\mathbf{J}$ et al [23] found that the prevalence of BHR was $13 \%$ (fall of $>$ or $=20 \%$ in FEV (1) up to a maximal cumulative dose of $2 \mathrm{mg}$ ), and $6 \%$ had asthma. A total of 143 women had undergone methacholine challenge within the risk window.

We observed a significant increase in BHR within the window of risk (odds ratio [OR], 2.3; 95\% CI, 1.27-4.29). A cyclic association pattern was confirmed by trigonometric functions. Effect modification by asthma status and oral contraceptive use was found, with lower OR in subjects without asthma and $\mathrm{OR}<1$ in women using OCs.

Sathish V et al[24] summarize the potential for sex steroids as useful biomarkers and therapeutic targets in these lung diseases as a basis for future translational research in the area of gender and individualized medicine.

Elizabeth A et al [25] found that Potential beneficial effects of estrogens on the systemic cardiovascular system with regard to hypertension would suggest a protective contribution of female sex steroids against the development or progression of PH. Indeed, in experimental animal models of $\mathrm{PH}$, estradiol attenuates or inhibits development of the disease. However, this protective nature is not realized clinically, thus forming the basis for an "estrogen paradox" in $\mathrm{PH}$.

Furthermore, compared with the systemic vasculature, less is known on the role of other steroids (progesterone, testosterone, and DHEA) in the development or modulation of $\mathrm{PH}$.

Several excellent reviews regarding sex steroids in the pulmonary vasculature cover these topics $[26,27,28,29,30]$.

Here, we briefly summarize what is known, and not known, and highlight the need for further consideration of sex steroid signaling in regard to $\mathrm{PH}$.
Fuseini $\mathrm{H}$ et al[31] women have an increased asthma prevalence compared to men. Further, women are more likely to have severe asthma and a later onset of asthma compared to men. Here, we review clinical and animal studies that have defined the role of sex hormones in airway inflammation, smooth muscle contraction, mucus production, and airway mechanics associated with asthma pathogenesis.

Understanding that the menstrual fall of estradiol and progesterone triggers asthmatic crises in vulnerable women may suggest new preventive strategies which are pathophysiologically oriented. This include stabilizing estradiol and progesterone/ progestins levels and reducing the hormone free interval (HFI), when OC is considered.

\section{Conclusion}

Higher values of lung functions during proliferative and secretary phases can be attributed to the higher concentrations of sex hormones specially progesterone because in most of the studies progesterone is known to cause relaxation of bronchial smooth muscle. Our study also suggests possible role of sex hormones especially progesterone in treating asthmatic females or at least reduction in the doses of bronchodilators can be done while concomitantly using progesterone. However further prospective controlled studies are needed to test this working hypothesis.

\section{Funding: Nil, Conflict of interest: None Permission of IRB: Yes}

\section{References}

1. Graziottin A, Zanello PP. [Menstruation, inflammation and comorbidities: implications for woman health]. Minerva Ginecol. 2015 Feb; 67(1): 21-34.[PubMed] www.ncbi.nlm.nih.gov

2. Graziottin A.The shorter, the better: A review of the evidence for a shorter contraceptive hormonefree interval..Eur J Contracept Reprod Health Care. 2016; 21(2): 93-105. [PubMed] www.ncbi. nlm. nih.gov

3. Heitkemper MM, Cain KC, Jarrett ME, Burr RL, Hertig V, Bond EF.Symptoms across the menstrual cycle in women with irritable bowel syndrome. Am J Gastroenterol. 2003 Feb; 98(2):420-30. [PubMed] www.ncbi.nlm.nih.gov 
4. Rubtsova K, Marrack P, Rubtsov AV. Sexual dimorphism in autoimmunity.J Clin Invest.2015 Jun; 125 (6):2187-93.[PubMed]www.ncbi.nlm. nih.gov

5. Zandman-Goddard G, Peeva E, Shoenfeld Y. Gender and autoimmunity. Autoimmun Rev. 2007 Jun; 6(6):366-72. [PubMed] www.ncbi.nlm.nih.gov

6. Graziottin A, Skaper SD, Fusco M. Inflammation and Chronic Pelvic Pain: A Biological Trigger for Depression in women? J Depress Anxiety. 2013;3:142-150.www.ncbi. nlm. nih. gov

7. Graziottin A, Skaper SD, Fusco M. Mast cells in chronic inflammation, pelvic pain and depression in women. Gynecol Endocrinol. 2014;30:472-7. doi: 8.3109/09513590.2014.911280. [PubMed] www.ncbi.nlm.nih.gov

8. Martin VT, Lipton RB. Epidemiology and biology of menstrual migraine. Headache. 2008;48 (Suppl3):S124-30. doi: 10.1111/j.1526-4610.2008. 01310.x.[PubMed]www.ncbi.nlm. nih.gov

9. Hassan S, Muere A, Einstein G. Ovarian hormones and chronic pain: A comprehensive review.Pain.2014;155:2448-60.doi:10.1016/j. pain. 2014.08.027.[PubMed]www.ncbi.nlm. nih.gov

10. Chandler MHH, Schuldheisz S, Phillips BA, Muse KN. Premenstrual asthma: the effect of estrogen on symptoms, pulmonary function, and $\beta 2$-receptors. Pharmacotherapy. 1997;17:224-234. [PubMed] www.ncbi.nlm.nih.gov

11. Agrawal AK, Shah A. Menstrual-linked asthma. J Asthma. 1997;34:539-545. [PubMed] www.ncbi.nlm.nih.gov

12. Miller MR, Hankinson J, Brusasco V, Burgos F, Casaburi R, Coates A, Crapo R, Enright P, van der Grinten CP, Gustafsson P, Jensen R, Johnson DC, MacIntyre N, McKay R, Navajas D, Pedersen OF, Pellegrino R, Viegi G, Wanger J. J; ATS/ERS Task Force. Standardisation of Spirometry. Eur Resp J.2005;26:319-338.[PubMed] www.ncbi.nlm. nih.gov

13. Berbic M, Fraser IS. Immunology of normal and abnormal menstruation. Womens Health (Lond
Engl) 2013;9:387-95. doi: 10.2217/whe.13.32. [PubMed] www.ncbi.nlm.nih.gov.

14. Lockwood CJ. Mechanisms of normal and abnormal endometrial bleeding. Menopause. 2011; 18:408-11. doi: 10.1097/gme.0b013e31820 bf288. [PMCfree article][PubMed]www.ncbi.nlm. nih.gov

15. Berbic $\mathrm{M}, \mathrm{Ng} \mathrm{CH}$, Fraser IS. Inflammation and endometrial bleeding. Climacteric. 2014;23:1-7. www.ncbi.nlm.nih.gov

16. Menzies FM, Shepherd MC, Nibbs RJ, Nelson SM. The role of mast cells and their mediators in reproduction8 pregnancy and labour. Hum Reprod Update. 2011;17:383-96. doi: 10.1093/humupd/ dmq053. [PubMed] www.ncbi.nlm.nih.gov

17. Muñoz-Cruz S, Mendoza-Rodríguez Y, NavaCastro KE, Yepez-Mulia L, Morales-Montor J. Gender-Related Effects of Sex Steroids on Histamine Release and FceRI Expression in Rat Peritoneal Mast Cells. J Immunol Res. 2015;2015: 351829. doi: 10.1155/2015/351829. [PMC free article] [PubMed] [Cross Ref] www. ncbi. nlm.nih.gov

18. Kim MS1, Chae HJ, Shin TY, Kim HM, Kim HR. Estrogen regulates cytokine release in human mast cells. Immunopharmacol Immunotoxicol. 2001;23:495-504. doi: 10.1081/IPH-100108596. [PubMed] [Cross Ref] www.ncbi.nlm.nih.gov

19. Vasiadi M, Kempuraj D, Boucher W, Kalogeromitros D, Theoharides TC. Progesterone inhibits mast cell secretion. Int J Immunopathol Pharmacol. 2006;19:787-94. [PubMed] www.ncbi. nlm. nih.gov

20. Osman M. Therapeutic implications of sex differences in asthma and atopy. Arch Dis Child. 2003;88:587-90. doi: 10.1136/adc.88.7.587. [PMC free article] [PubMed] [Cross Ref] www.ncbi.nlm. nih.gov

21. Zhao XJ, McKerr G, Dong Z, Higgins CA, Carson J, Yang ZQ, et al. Expression of oestrogen and progesterone receptors by mast cells alone, but not lymphocytes, macrophages or other immune cells in human upper airways. Thorax. 2001;56: 205-11. doi: 10.1136/thorax.56.3.205. [PMCfree article][PubMed][CrossRef]www.ncbi. nlm.nih.gov 
22. Alessandra Graziottin et al Perimenstrual asthma: from pathophysiology to treatment strategies. Multidiscip Respir Med. 2016; 11: 30. Published online 2016 Aug 1. doi: 10.1186/s 40248-016-0065-0 www.ncbi.nlm.nih.gov

23. Dratva $\mathbf{J}^{1}$, Schindler CPerimenstrual increase in bronchial hyperreactivity in premenopausal women: results from the population-based SAPALDIA 2 cohort. J Allergy Clin Immunol. 2010 Apr;125(4):823-9. www.ncbi.nlm.nih.gov

24. Venkatachalem Sathish Sex Steroid Signaling: Implications for Lung Diseases. Pharmacol Ther. 2015 Jun; 150: 94-108. www.ncbi.nlm.nih.gov

25. Elizabeth A. Townsend Sex Differences and Sex Steroids in Lung Health and Disease. Endocr Rev. 2012 Feb; 33(1): 1-47. Published online 2012 Jan 12. www.ncbi.nlm.nih.gov

26. Pugh ME, Hemnes A. Development of pulmonary arterial hypertension in women: interplay of sex hormones and pulmonary vascular disease. Womens Health (Lond). 2010 Mar; 6(2): 285-96.[PubMed] www.ncbi.nlm.nih.gov

27. Sakao S, Tanabe N, Tatsumi K. The estrogen paradox in pulmonary arterial hypertension. Am $\mathbf{J}$
Physiol Lung Cell Mol Physiol. 2010 Oct; 299(4): L435-8.[PubMed] www.ncbi.nlm.nih.gov

28. Tofovic SP. Estrogens and development of pulmonary hypertension: interaction of estradiol metabolism and pulmonary vascular disease. J Cardiovasc Pharmacol. 2010 Dec; 56(6):696-708. [PubMed] www.ncbi.nlm.nih.gov

29. Lahm T, Crisostomo PR, Markel TA, Wang M, Weil BR, Novotny NM, Meldrum DR. The effects of estrogen on pulmonary artery vasoreactivity and hypoxic pulmonary vasoconstriction: potential new clinical implications for an old hormone. Crit Care Med. 2008 Jul; 36(7):2174-83. [PubMed] www. ncbi. nlm. nih.gov

30. Smith AM, Bennett RT, Jones TH, Cowen ME, Channer KS, Jones RD. Characterization of the vasodilatory action of testosterone in the human pulmonary circulation. Vasc Health Risk Manag. 2008;4(6):1459-66.[PubMed]www.ncbi.nlm.nih. gov

31. Fuseini $\mathrm{H}$ Mechanisms Driving Gender Differences in Asthma. Curr Allergy Asthma Rep. 2017 Mar;17(3):19. www.ncbi.nlm.nih.gov

\section{How to cite this article?}

Dudhamal V B, Satish. Lung function tests in different phases of menstrual cycle. Int J Med Res Rev 2017;5(08):780-785.doi:10.17511/ijmrr. 2017.i08.01. 